\title{
A New Method for Analysis of Disulfide-Containing Proteins by Matrix-Assisted Laser Desorption Ionization (MALDI) Mass Spectrometry
}

\author{
Hongmei Yang, ${ }^{\mathrm{a}, \mathrm{b}}$ Ning Liu, ${ }^{\mathrm{a}, \mathrm{c}}$ Xiaoyan Qiu, ${ }^{\mathrm{a}}$ and Shuying Liu ${ }^{\mathrm{a}, \mathrm{d}}$ \\ ${ }^{a}$ Changchun Center of Mass Spectrometry, Changchun Institute of Applied Chemistry, Chinese Academy of \\ Sciences, Changchun, P.R. China \\ ${ }^{b}$ Graduate School of the Chinese Academy of Sciences, Beijing, P.R. China \\ ' Jilin University, Changchun, P.R. China \\ ${ }^{\mathrm{d}}$ Changchun University of Chinese Medicine, Changchun, P.R. China
}

\begin{abstract}
A simple and high-throughput method for the identification of disulfide-containing peptides utilizing peptide-matrix adducts is described. Some commonly used matrices in MALDI mass spectrometry were found to specifically react with sulfhydryl groups within peptide, thus allowing the observation of the peptide-matrix adduct ion $\left[\mathrm{M}+n+n^{\prime} \text { matrix }+\mathrm{H}\right]^{+}$or $\left[\mathrm{M}+n+n^{\prime}\right.$ matrix $+\mathrm{Na}^{+}\left(n=\right.$ the number of cysteine residues, $\left.n^{\prime}=1,2, \ldots, n\right)$ in MALDI mass spectra after chemical reduction of disulfide-linked peptides. Among several matrices tested, $\alpha$-cyano-4hydroxycinnamic acid (CHCA, molecular mass $189 \mathrm{Da}$ ) and $\alpha$-cyano-3-hydroxycinnamic acid (3-HCCA) were found to be more effective for MALDI analysis of disulfide-containing peptides/ proteins. Two reduced cysteines involved in a disulfide bridge resulted in a mass shift of $189 \mathrm{Da}$ per cysteine, so the number of disulfide bonds could then be determined, while for the other matrices (sinapinic acid, ferulic acid, and caffeic acid), a similar addition reaction could not occur unless the reaction was carried out under alkaline conditions. The underlying mechanism of the reaction of the matrix addition at sulfhydryl groups is proposed, and several factors that might affect the formation of the peptide-matrix adducts were investigated. In general, this method is fast, effective, and robust to identify disulfide bonds in proteins/peptides. (J Am Soc Mass Spectrom 2009, 20, 2284-2293) (c) 2009 American Society for Mass Spectrometry
\end{abstract}

$\mathrm{P}$ ost-translational modifications of protein are crucial to maintain its structure and fulfill the biological functions. Disulfide bond formation, a major determinant of maintaining the 3D structure of proteins, is one of the most notable post-translational modifications. The disulfide bridges in a protein cannot be predicted from its amino acid sequence; therefore, the determination of disulfide bonds in a protein will provide useful information on its 3D structure and stability, and contribute to the understanding of its structural-functional relationship [1-3]. There are a number of existing methods for the determination of disulfide bonds within proteins as described in the literatures. Among them, the NMR-based approach is efficient for analyzing disulfide-rich peptides [4-6]. However, it has the limitation of needing considerable amounts of the analytes. With the development of mass spectrometry, great improvements in speed and sensitivity for disulfide bond analysis have been made. The first report of insulin reduction on a mass spectrometry

Address reprint requests to Professor S. Liu, Changchun Center of Mass Spectrometry, Changchun Institute of Applied Chemistry, Chinese Academy of Sciences, 5625 Renmin Street, Changchun 130022, P.R. China. E-mail: syliu@ciac.jl.cn, syliu19@yahoo.com.cn probe appeared in 1986 [7]. The technique based on reduction during a mass spectrometry experiment was also employed by other groups [8,9]. A widely accepted approach based on partial reduction and alkylation was reported [10-13]. The approach is laborious because most steps need optimizations.

Interestingly, it was found that 1,5-diaminonaphthalene (1,5-DAN) can reduce disulfide bonds in peptides in the laser plume [14, 15]. Using this feature of 1,5-DAN, disulfide linkages in the proteins were characterized by the comparison of mass differences between the reduced, partially reduced, and nonreduced molecular ions. However, in the interpretation of the obtained data, one must exercise extreme caution because 1,5DAN can dramatically enhance in-source decay (ISD) fragmentation [16]. Recently, a screening method that uses ISD of disulfide bonds for identification of disulfidelinked peptides in mass spectra has been developed [17, 18]. Zhang and Kaltashov reported a method to detect disulfide-linked proteins using the broadband collisionactivated dissociation (CAD) in the negative ion mode [19]. Selective detection of products of disulfide bond dissociation in the gas phase is difficult because of the presence of abundant ions produced by backbone cleav- 
age in broadband CAD spectra. Several recent studies have reported cleavages of the $\mathrm{S}-\mathrm{S}$ or $\mathrm{S}-\mathrm{C}$ bond at disulfide linkages using MALDI-TOF/TOF-MS, ESIMS/MS, or LIFT-TOF/TOF-MS [20-26], in which a strategy for the selective elimination of hydrogen disulfide $\left(\mathrm{H}_{2} \mathrm{~S}_{2}\right)$ is widely employed. To enhance the selective cleavages, alkali and alkaline earth metal enolate complexes were used [20-23]. A novel analytical strategy developed by $\mathrm{Xu}$ used a new tandem MS database search program (MassMatrix) to identify disulfidelinked peptides [27]. The algorithm based on the statistical scoring model in MassMatrix facilitates the $\mathrm{MS}^{n}$ data processing.

In the mass spectrometric analysis of disulfide-linked peptides using MALDI-TOF-MS, we observed prominent peptide-matrix adduct ions when reduction of disulfide bonds by dithiothreitol (DTT) was performed on target plate. To further investigate this matrix addition phenomenon, we tested 12 other common matrices. A variety of factors including $\mathrm{pH}$, the molar ratio of matrix to disulfide-linked peptide, and reducing reagents were also used. A mechanism of the observed adduction between sulfhydryls and $\alpha-, \beta$-unsaturated matrices is proposed. To the best of our knowledge, this is the first detailed study on the matrix addition reaction as well as its application to the analysis of disulfidecontaining proteins.

\section{Experimental}

\section{Materials and Reagents}

CHCA, 3-HCCA, sinapinic acid (SA), ferulic acid (FA), caffeic acid (CA), trans-3-indoleacrylic acid (IAA), dithranol (DT), 2-(4-hydroxyphenylazo)benzoic acid (HABA), 2,5-dihydroxybenzoic acid (DHB), 3-hydroxypicolinic acid (3-HPA), 2,4,6-trihydroxy acetophenone (THAP), 2,6dihydroxy acetophenone (DHAP), 3-aminoquinolin, human insulin, oxytocin, and tris(2-carboxyethyl)phosphine (TCEP) were purchased from Sigma (St. Louis, MO, USA). Scheme 1 shows structures of all the tested matrices. Octreotide was supplied by GL Biochem Ltd. (Shanghai, China). Lysozyme was purchased from Sino-American Biotechnology Company. $\beta$-Mercaptoethanol (ME) was acquired from Dingguo Bio-Technology Co., Ltd (Beijing,
China). Trypsin (sequencing grade) and DTT were purchased from Promega (Madison, WI, USA). Acetonitrile (ACN, HPLC grade) was obtained from Fisher Chemical Company (Fair Lawn, NJ, USA). Trifluoroacetic acid (TFA, HPLC grade) and formic acid (HPLC grade) were bought from TEDIA Company (Fairfield, OH, USA). All other chemicals used in this study were analytical grade and were used without further purification. Ultrapure water (specific conductivity, $18.2 \mathrm{M} \Omega / \mathrm{cm}$ ) was produced by a MilliQ device (Millipore, Milford, MA, USA).

\section{Proteolytic Digestion}

Human insulin and lysozyme were digested separately at $37^{\circ} \mathrm{C}$ by trypsin in $50 \mathrm{mM} \mathrm{NH} \mathrm{NHCO}_{3}$ at $\mathrm{pH} 7.8$. Enzyme/substrate ratio was adjusted to 1:50, and digestion was performed for $6 \mathrm{~h}$. The digestion was terminated by freezing at $-20{ }^{\circ} \mathrm{C}$ without being adjusted to acidity.

\section{Sample Preparation}

Sample preparation for MALDI-MS. Sample concentration was adjusted to $1 \mathrm{mg} / \mathrm{mL}$ before analysis. The following compounds in $50 \mathrm{mM} \mathrm{NH} \mathrm{NCO}_{3} / \mathrm{NH}_{4} \mathrm{OH}$ (pH 9.0) were used as reductants: (1) DTT (40 mM), (2) TCEP (40 mM), (3) ME (100-1000 mM). The following compounds were used as MALDI matrices: (1) CHCA, (2) 3-HCCA, (3) SA, (4) FA, (5) CA, (6) IAA, (7) DHB, (8) HABA, (9) THAP, (10) DHAP, (11) HPA, (12) DT, and (13) 3-aminoquinolin. All the matrices were used at a concentration of $45 \mathrm{mM}$ in $50 \%$ water/acetonitrile except HABA (in ethanol) and DT (in tetrahydrofuran). On-target reduction was performed under following conditions: A $0.5 \mu \mathrm{L}$ each of the tryptic digests of the proteins and the peptide solutions was mixed on the stainless steel target with a $0.5 \mu \mathrm{L}$ aliquot of each of freshly prepared reductant solutions. After $20 \mathrm{~min}$ at room temperature, $0.5 \mu \mathrm{L}$ matrix samples were spotted on the MALDI plate; $5 \%$ TFA water might be used to adjust the $\mathrm{pH}$ of analyte/reductant/matrix complex when needed. The mixture was dried at ambient temperature before MALDI analysis. For complete reduction of the disulfide bond-containing peptides in solu-
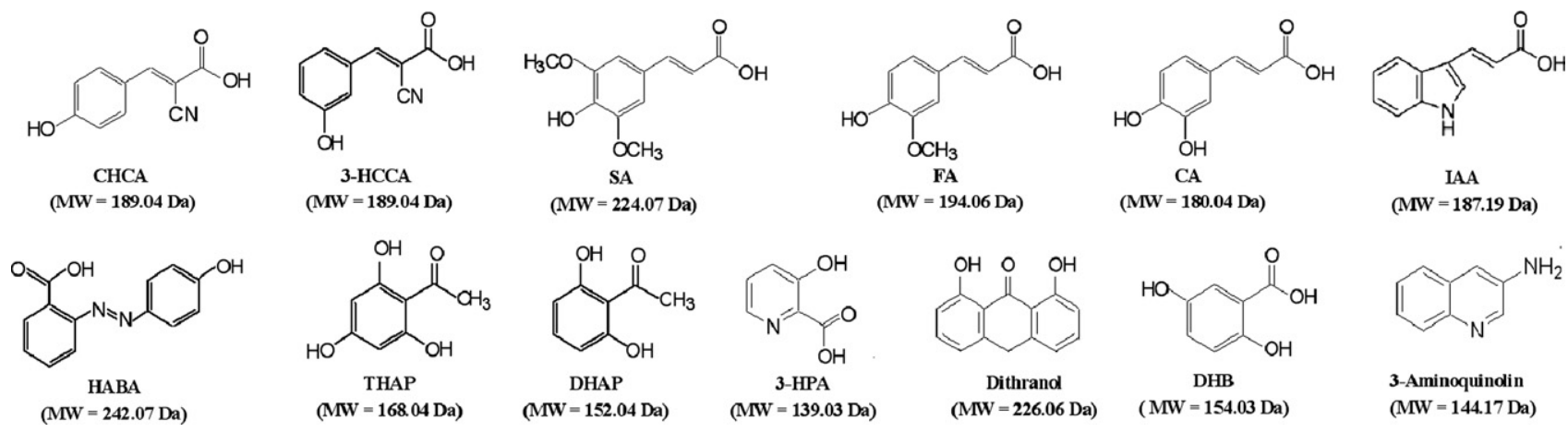

3-Aminoquinolin (MW = 144.17 Da)

Scheme 1. Structures, abbreviations, and molecular weights of matrices used in this study. 
tion, $50 \mu \mathrm{L}$ each of octreotide and oxytocin solutions were first mixed with the same volume of each reductant solution for $1 \mathrm{~h}$ at $37^{\circ} \mathrm{C}$ and then incubated for different times $(0.5-4 \mathrm{~h})$ at $37^{\circ} \mathrm{C}$ with $50 \mu \mathrm{L}$ or $100 \mu \mathrm{L}$ each of matrix solutions described above at final $\mathrm{pH}$ 2-8.5. Aliquots $(1.5 \mu \mathrm{L})$ were used for MALDI-MS analysis without further purification.

Sample preparation for HPLC-ESI-MS. An aqueous solution of octreotide ( $50 \mu \mathrm{L} ; 1 \mathrm{mg} / \mathrm{mL})$ was mixed with a solution $(50 \mu \mathrm{L})$ of DTT in $50 \mathrm{mM} \mathrm{NH}_{4} \mathrm{HCO}_{3} / \mathrm{NH}_{4} \mathrm{OH}$ buffer ( $\mathrm{pH}$ 9.0). The final concentration of DTT was 20 $\mathrm{mM}$, resulting in a molar ratio of DTT to octreotide of 41:1. After the mixed solution was incubated at $37^{\circ} \mathrm{C}$ for $1 \mathrm{~h}$, a solution of $45 \mathrm{mM} \mathrm{CHCA} \mathrm{in} \mathrm{50 \%} \mathrm{water/}$ acetonitrile $(50 \mu \mathrm{L})$ was added. The mixture was incubated at $37^{\circ} \mathrm{C}$ for another $1 \mathrm{~h}$. The molar ratio of CHCA to octreotide was $46: 1$. The peptide mixture was lyophilized and redissolved in $100 \mu \mathrm{L}$ of HPLC mobile phase for subsequent HPLC separation.

\section{MALDI-MS}

MALDI mass spectra were acquired on a MALDI-TOF mass spectrometer (Voyager DE-STR; Applied Biosystems, Foster City, CA, USA) equipped with a $337 \mathrm{~nm}$ nitrogen laser. The instrument was operated in positive ion reflectron mode. The accelerating voltage was 20 $\mathrm{kV}$, while the grid voltage and delay time were set at 65\% and 100 ns, respectively. The laser intensity, optimized for each sample, was attenuated to just above the threshold of ionization for each sample. The laser was fired at a frequency of $3 \mathrm{~Hz}$, and spectra were recorded from the sum of 50 laser shots. Each preparation technique evaluated was prepared and examined in triplicate, with the best spectrum in terms of relative intensity of analyte used for comparison with other techniques. Spectra were externally calibrated using singly charged monoisotopic peaks of angiotensin I (1296.6853 Da), ACTH (clip 1-17) (2093.0867 Da), and ACTH (clip 18-39) (2465.1989 Da). Postacquisition processing of data was performed utilizing the Data Explorer software (Applied Biosystems).

\section{HPLC-ESI-MS}

High-performance liquid chromatography was performed on a Waters 2695 system (Milford, MA, USA) consisting of an automatic sampler, a column heater, and a quaternary high-pressure pump. Separations of analytes were carried out using a Diamonsil $\mathrm{C}_{18}$ column (250 mm $\times 4.6 \mathrm{~mm}$ i.d., $5 \mu \mathrm{m}$; Dikma, Beijing, China). The chromatography was performed at $25^{\circ} \mathrm{C}$. The mobile phase consisted of acetonitrile $/ 0.1 \%$ formic acid in water $(20: 80, \mathrm{vol} / \mathrm{vol})$ at a flow rate of $0.5 \mathrm{~mL} / \mathrm{min}$. Mass spectrometric detection was carried out on a Finnigan LCQ ion trap mass spectrometer (San Jose, CA, USA) equipped with an ESI source. The spray voltage was set at $4.5 \mathrm{kV}$ in the positive ion mode. The capillary voltage was fixed at $30 \mathrm{~V}$, and its temperature was maintained at $250{ }^{\circ} \mathrm{C}$. Nitrogen was used as both the sheath gas, at a flow rate of $60 \mathrm{arb}$, and the auxiliary gas at a flow rate of 30 arb. Automated acquisition of mass spectra was executed by data-dependent scanning using Xcalibur software (Thermo Finnigan).

\section{Results and Discussion}

\section{Observation of Adducts of Matrix and Sulfhydryl-Containing Peptide}

In this study, we selected oxytocin (simplified as $\mathrm{M}_{1}$ ) and octreotide $\left(\mathrm{M}_{2}\right)$ as examples, and the structures are listed in Scheme 2. Figure $1 \mathrm{a}$ and $\mathrm{b}$ present MALDI mass spectra of oxytocin with CHCA matrix before and after reduction by DTT, and Figure $1 \mathrm{c}$ and d correspond to those of octreotide, respectively. In Figure 1a, a base peak corresponds to $\left[\mathrm{M}_{1}+\mathrm{Na}\right]^{+}$at $m / z$ 1029.47, and a weak one corresponds to $\left[\mathrm{M}_{1}+\mathrm{K}\right]^{+}$at $m / z$ 1045.37; in Figure 1c, a base peak $\left[\mathrm{M}_{2}+\mathrm{H}\right]^{+}$at $m / z 1019.42$ and a minor peak $\left[\mathrm{M}_{2}+\mathrm{Na}\right]^{+}$at $\mathrm{m} / \mathrm{z} 1041.37$ are observed. A different situation occurred in Figure 1a and c. In the oxytocin case, the base peak is $\left[\mathrm{M}_{1}+\mathrm{Na}\right]^{+}$, but the base peak is $\left[\mathrm{M}_{2}+\mathrm{H}\right]^{+}$for octreotide in Figure 1c. Comparing Figure $1 \mathrm{a}$ with $1 \mathrm{~b}$ as well as Figure $1 \mathrm{c}$ with $\mathrm{d}$, the 2-Da mass shift indicates the reduction of the disulfide bond.

Additionally, the matrix-peptide adducts are also observed as shown in Figure $1 \mathrm{~b}$ and $\mathrm{d}$. Comparison of the spectrum in Figure $1 \mathrm{~b}$ with that in Figure 1a obtained in the absence of DTT reveals that the mass spectrum in Figure $1 \mathrm{~b}$ contains three dominant new signals at $m / z 1220.50,1409.53$, and 1387.54 , which are attributed to $\left[\mathrm{M}_{1}+2+\mathrm{CHCA}+\mathrm{Na}\right]^{+},\left[\mathrm{M}_{1}+2+2\right.$ $\mathrm{CHCA}+\mathrm{Na}]^{+}$, and $\left[\mathrm{M}_{1}+2+2 \mathrm{CHCA}+\mathrm{H}\right]^{+}$, respectively. In Figure $1 \mathrm{~d}$, adduct ions $\left[\mathrm{M}_{2}+2+\right.$ $\mathrm{CHCA}+\mathrm{H}]^{+},\left[\mathrm{M}_{2}+2+\mathrm{CHCA}+\mathrm{Na}\right]^{+}$, and $\left[\mathrm{M}_{2}+\right.$ $2+\mathrm{CHCA}+\mathrm{K}^{+}$at $m / z 1210.47,1232.44$, and 1248.42, as well as $\left[\mathrm{M}_{2}+2+2 \mathrm{CHCA}+\mathrm{H}\right]^{+}$at $\mathrm{m} / z 1399.50$ are also observed. The observation of $\left[\mathrm{M}_{1(2)}+2+\mathrm{CHCA}+\right.$ $\mathrm{H}^{+}$is consistent with the result reported by Glocker's group [28, 29]. On-target reduction was performed with TCEP in the presence of the CHCA matrix in their reports. However, they only observed the adduct ion [peptide $+2+\mathrm{CHCA}+\mathrm{H}]^{+}$and did not report the result with other matrices and the interpretation of the observed phenomenon. In an attempt to gain a better insight into this phenomenon, several other commonly used matrices were also tried. Among the matrices (see Scheme 1), we found that 3-HCCA, SA, FA, and CA were also able to form matrix-adducts of reduced forms of disulfide-containing peptides under $\mathrm{pH} 7.5$ (Supplemental Information, Figure S-1, which can be found in the electronic version of this article). The data for the use of 3-HCCA as matrix are very similar to those for CHCA and not provided in this report. 

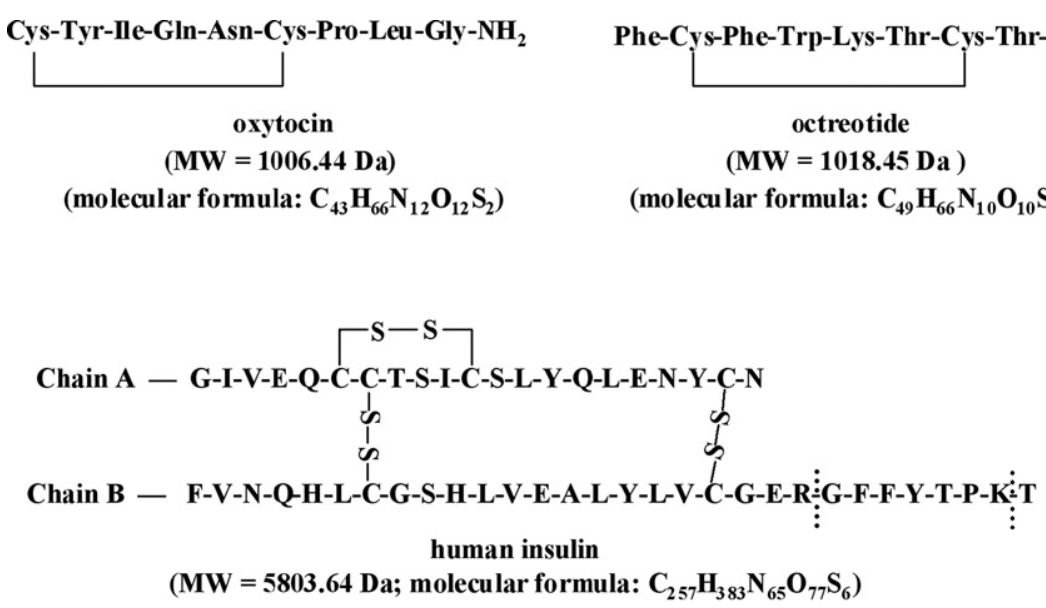

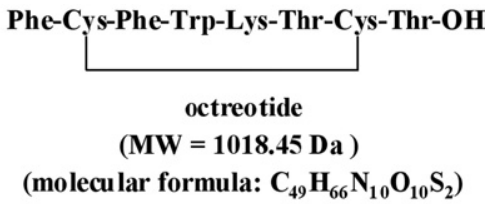

(molecular formula: $\mathrm{C}_{49} \mathrm{H}_{66} \mathrm{~N}_{10} \mathrm{O}_{10} \mathrm{~S}_{2}$ )

\section{KVFGRCELAA AMKRHGLDNY RGYSLGNWVC AAKFESNFNT QATNRNTDGS TDYGILQINS RWWCNDGRTP GSRNLCNIPC SALLSSDITA SVNCAKKIVS DGDGMNAWVA WRNRCKGTDV QAWIRGCRL [disulfide bridge: Cys 6-Cys 127, Cys 30-Cys 115, Cys 64-Cys 80, Cys 76-Cys 94] \\ lysozyme \\ $\left(M W=14296.80\right.$ Da; molecular formula: $\left.\mathrm{C}_{613} \mathrm{H}_{950} \mathrm{~N}_{192} \mathrm{O}_{186} \mathrm{~S}_{10}\right)$}

Scheme 2. Structures and molecular weights of oxytocin, octreotide, insulin, and lysozyme examined in this study.

\section{Generation of Peptide-Matrix Adducts in Solution} or in Gas Phase

To clarify this question, we took octreotide as an example. Octreotide solution was treated with DTT and then incubated with CHCA, followed by LC/ESI-MS analysis. The LC/ESI-MS chromatogram of the incubation mixture is shown in Figure 2a. Two peaks, I and II, are obtained in Figure $2 \mathrm{a}$. Figure $2 \mathrm{~b}$ and c correspond to the mass spectra of peak I and II, respectively. As shown in Figure $2 b$ and c, peak II corresponds to a pure compound, while peak I is a poorly separated one. The ESI mass spectrum of the fraction eluted at peak II (Figure 2c) shows a strong signal at $\mathrm{m} / \mathrm{z} 1021.4$ and a small signal at $\mathrm{m} / \mathrm{z} 510.4$, correspond- ing to the singly charged ion and the doubly charged ion of the reduced octreotide, respectively. Peak I contains three components as indicated in Figure $2 b$. The most abundant ion in the full-scan mass spectrum of peak I (Figure 2b) is a singly charged adduct of reduced octreotide and one CHCA at $m / z$ 1210.3. The two minor ions at $m / z 1021.3$ and 1399.3 correspond to the reduced octreotide, the adduct of reduced octreotide, and two CHCA. The evidence for the generation of peptide-matrix adducts in the solution phase during peptide reduction with DTT and incubation with CHCA was provided by LC/ESI-MS analysis.

It is commonly known among mass spectrometrists that matrix association is observed to some extent in the
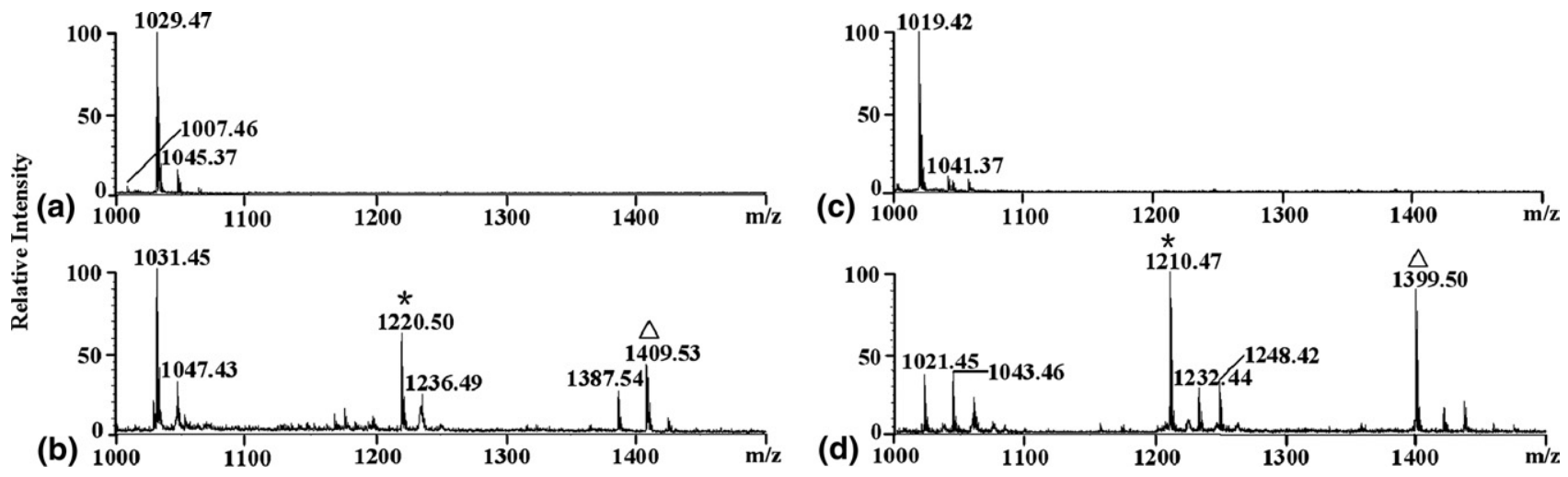

Figure 1. MALDI mass spectra in positive ion mode of (a) oxytocin, (b) oxytocin after on-target reduction by DTT, (c) octreotide, and (d) octreotide after on-target reduction by DTT using CHCA as the matrix under $\mathrm{pH}$ 7.5. Signals labeled with an asterisk are assigned to peptide-matrix 1:1 adducts. Signals corresponding to peptide-matrix 1:2 adducts are labeled with an open triangle. 


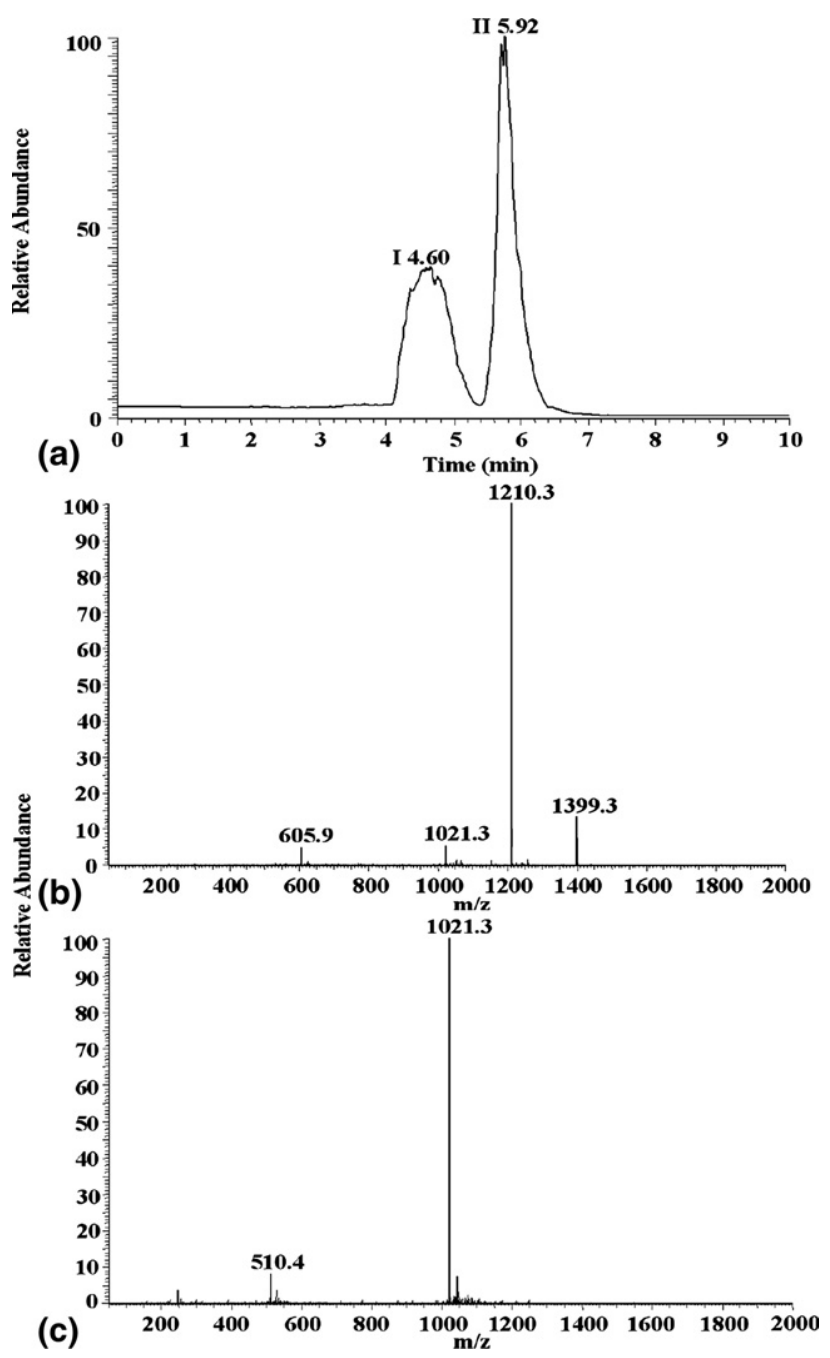

Figure 2. (a) Total ion chromatogram of a solution containing 0.5 $\mathrm{mg} / \mathrm{mL}$ of reduced octreotide incubated with $45 \mathrm{mM} \mathrm{CHCA}$. (b) ESI mass spectrum associated with the TIC peak I. (c) ESI mass spectrum associated with the TIC peak II.

gas phase. The matrix adduct signals reported in the literature [30-32], most of which are formed as noncovalent species in the gas phase, are different from those observed in our report. The peptide-matrix adducts observed in our study are based on the interaction between the $-\mathrm{SH}$ group of $\mathrm{Cys}$ and an $\alpha$-, $\beta$-unsaturated matrix in solution.

\section{The $\mathrm{pH}$ Dependence and Mechanism of the Generation of Peptide-Matrix Adducts}

A solution of $0.5 \mu \mathrm{L}$ octreotide $(1 \mathrm{mg} / \mathrm{mL})$ after ontarget reduction by DTT using the same volume of $\mathrm{CHCA}, \mathrm{SA}$, and CA as matrices under alkaline condition ( $\mathrm{pH}$ 8.5) were recorded the MALDI mass spectra shown in Figure 3a-c, respectively. Moreover, the similar result was obtained for FA as matrix at the same $\mathrm{pH}$ (Supplemental Information, Figure S-2a). Curiously, in the case of IAA, although the peptide-matrix adduct peak was not large relative to the base peak, it was present (Supplemental Information, Figure S-2b). Here, it should be noticed that no peptide-matrix adducts were observed for other matrices, even under strong alkaline conditions. Through comparison of mass spectrum in Figure 3a with that in Figure 1d, it can be readily found that the higher the $\mathrm{pH}$, the higher the intensity of peptide-CHCA adducts. For the other matrices case, such as SA, CA, and FA, the matrix addition reaction seemed to be more sensitive to $\mathrm{pH}$ than the case of CHCA. Take cases of SA and CA; a dramatic increase of the relative abundance of not only $\left[\mathrm{M}_{2}+2+\right.$ matrix $+\mathrm{H}^{+}$labeled with ${ }^{*}$ (an asterisk), but also $\left[\mathrm{M}_{2}+2+2 \text { matrix }+\mathrm{H}\right]^{+}$labeled with $\Delta$ (an open triangle) is observed in Figure $3 b$ and c.

The peptide-matrix adducts disappeared at $\mathrm{pH}<2.5$ for CHCA and $\mathrm{pH}<6.5$ for SA, FA, and CA. As for IAA, only a little adduct was observed even in extremely alkaline conditions owing to the structural difference. So alkaline conditions were favorable to the formation of peptide-matrix adducts.

Considering structures of the matrices and MS data, the following deduction can be made; this adduct formation is related to the carbon-carbon double bond adjacent to the carboxyl group. The present data appear to be consistent with current literature, which suggests alkylation of cysteine in proteins via reaction with $\alpha$-, $\beta$-unsaturated compounds (notably acrylonitrile, acrylamide, and methyl acrylate) [33-37]. Based on our experimental data, we proposed a reaction mechanism of a free $-\mathrm{SH}$ group in proteins and an $\alpha$-, $\beta$-unsaturated matrix as shown in Scheme 3. Because the proton affinity of cysteine is $216.1 \mathrm{kcal} \cdot \mathrm{mol}^{-1}$, which is rather basic [38], so a free $-\mathrm{SH}$ group of proteins releases a

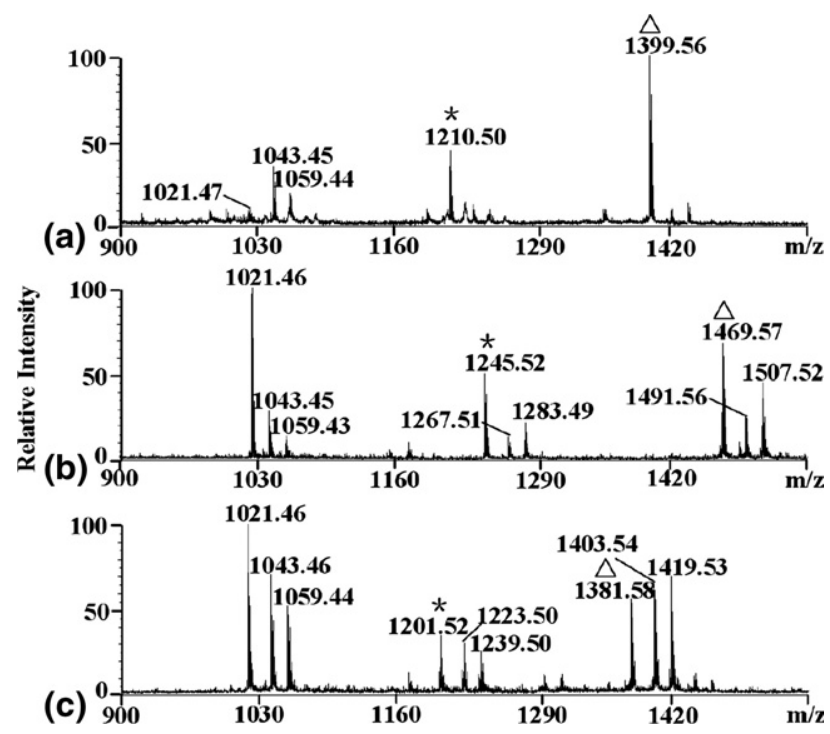

Figure 3. MALDI mass spectra of octreotide obtained after on-target reduction by DTT using (a) CHCA, (b) SA, and (c) CA as the matrices at final $\mathrm{pH}$ 8.5. Signals labeled with an asterisk are assigned to peptide-matrix 1:1 adducts. Signals corresponding to peptide-matrix 1:2 adducts are labeled with an open triangle. 


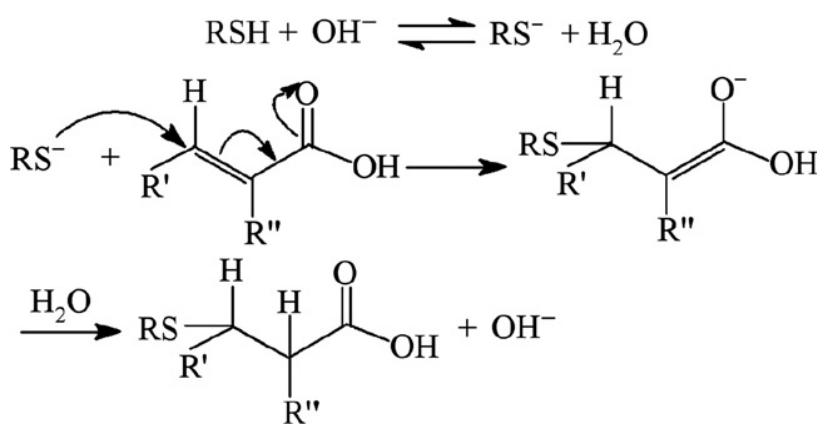

Scheme 3. A proposed reaction mechanism of a free $-\mathrm{SH}$ group of proteins and an $\alpha$-, $\beta$-unsaturated matrix.

proton only under alkaline condition. Then $\mathrm{RS}^{-}$attacks at the double-bond of an $\alpha^{-}, \beta$-unsaturated matrix. Theoretically, it is difficult to have a nucleophilic addition reaction for an $\alpha-, \beta$-unsaturated carboxylic acid. However, the nucleophilic addition reaction can occur if $-\mathrm{R}^{\prime \prime}$ is an electrophilic group, like cyano radical $-\mathrm{CN}$. CHCA and 3-HCCA are regarded as derivatives of acrylonitrile, which are favorable to the Michael addition reaction; thus distinct peptide-matrix adducts were observed using CHCA or 3-HCCA as a matrix. According to the reaction mechanism, the results of $\mathrm{pH}$ effect might be interpreted as follows: The nucleophilic addition reaction can occur easily at sulfhydryl group of cysteine under high $\mathrm{pH}$ due to easy release of a proton. Our experimental results show that the ability for modification of cysteine by the matrices tried is as follows: $\mathrm{CHCA} \approx 3-\mathrm{HCCA} \gg \mathrm{SA} \approx \mathrm{FA} \approx \mathrm{CA}$.

\section{Effect of Molar Ratios, Incubation Time, and Reductants}

Solutions ( $\mathrm{pH}$ 7.5) containing fixed concentration (1 $\mathrm{mg} / \mathrm{mL}$ ) of reduced oxytocin and two volumes (the same and 2-fold volumes of oxytocin solution) of each matrix were analyzed by MALDI-MS, i.e., the molar ratios of matrix/oxytocin of $46: 1$ and 92:1 were employed, and the representative spectra are shown in Figure 1b (46:1), Figure S-1a-c (46:1), Figure S-3 (92:1), and Figure 4 (92:1). From the above figures, an increase of the molar ratio of matrix to oxytocin significantly enhanced the intensities of adducts. As to IAA, under high $\mathrm{pH}$ and high molar ratios of matrix to peptide, it was hard to find the adduct signals (see Figure S-2b and Figure S-3c). We have conducted the experiment with different incubation times, which did not significantly affect the addition reaction.

Three common reductants for disulfide-containing peptides were evaluated in this work. When ME was used as reductant on target or in solution, peptidematrix adducts were observed at the molar ratios of ME/oxytocin < 100:1 (data not shown). Formation of mixed disulfides between the cysteinyl thiol-containing peptide and ME was dominant, and no matrix adducts were observed when higher molar ratios of $\mathrm{ME}$ to disulfide-linked peptide ( $>150: 1)$ were used for reduction of disulfide bonds. This indicates that ME competes with an $\alpha-, \beta$-unsaturated matrix for binding to the cysteinyl thiol in liquid phase. Our data support the report of Spiess et al., in which peptide-CHCA adduct ions were not observed at the molar ratio of $\mathrm{ME} /$ peptide $>150: 1$ in solution [29]. Peptide-matrix adducts were observed after complete reduction of the disulfide-linked peptides in solution using TCEP or DTT, but ME in our study, because the reaction of cysteinyl thiol-containing peptide and $\mathrm{ME}$, competed with the generation of peptidematrix adduct. The former reaction may be faster than the later one, so the adducts were not observed when ME was used as a reductant. Therefore, the reductants, TCEP and DTT, were better than ME without interfering analysis of disulfide containing peptides. As a result, both TCEP and DTT are recommended to use for disulfide analysis.

\section{Application for the Analysis of Disulfide-Rich Proteins}

To prove its feasibility for identifying peptides with a disulfide linkage in complex mixtures, we examined the tryptic digests of insulin and lysozyme. Insulin is a small model protein comprised of two peptide chains with two inter-disulfide bond bridges in addition to an intra-disulfide bond on the A-chain (Scheme 2). The amino acid sequence of insulin contains two potential cleavage sites for trypsin, which is indicated by dashed lines in Scheme 2. The mass spectrum of the tryptic digests of insulin using CHCA as matrix is presented in Figure 5a, which shows two major monoisotopic peaks at $m / z 859.47$ and 4863.23 . On-target reduction of human insulin with DTT followed by spotting $45 \mathrm{mM}$ DHB solution yielded the MALDI-TOF spectrum in Figure $5 b$. In this case, the ion signal at $m / z 4863.23$ disappears, and two new ion signals for the peptide of the A-chain (A1-A21) containing 4 cysteines $(\mathrm{m} / \mathrm{z} 2383.00)$ and the

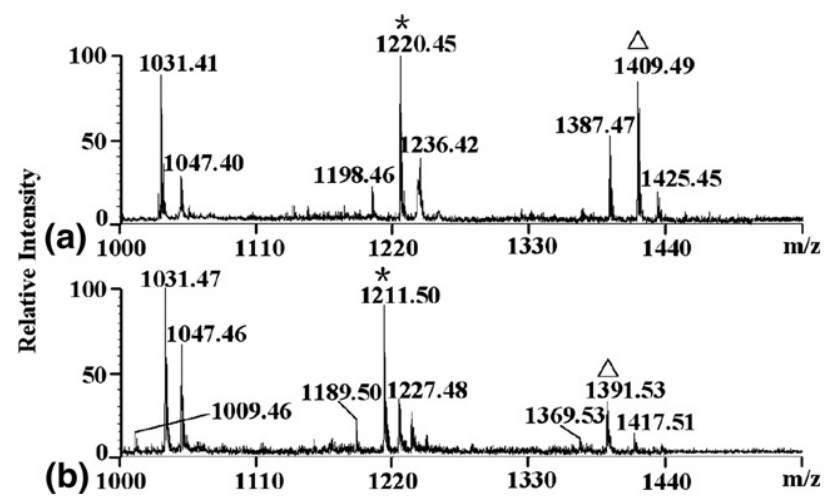

Figure 4. MALDI mass spectra of oxytocin obtained after ontarget reduction by DTT using (a) CHCA and (b) CA as the matrices at the molar ratio of matrix/oxytocin of 92:1 adopted final $\mathrm{pH}$ 7.5. Signals labeled with the asterisk are assigned to peptide-matrix 1:1 adducts. Signals corresponding to peptidematrix 1:2 adducts are labeled with an open triangle. 


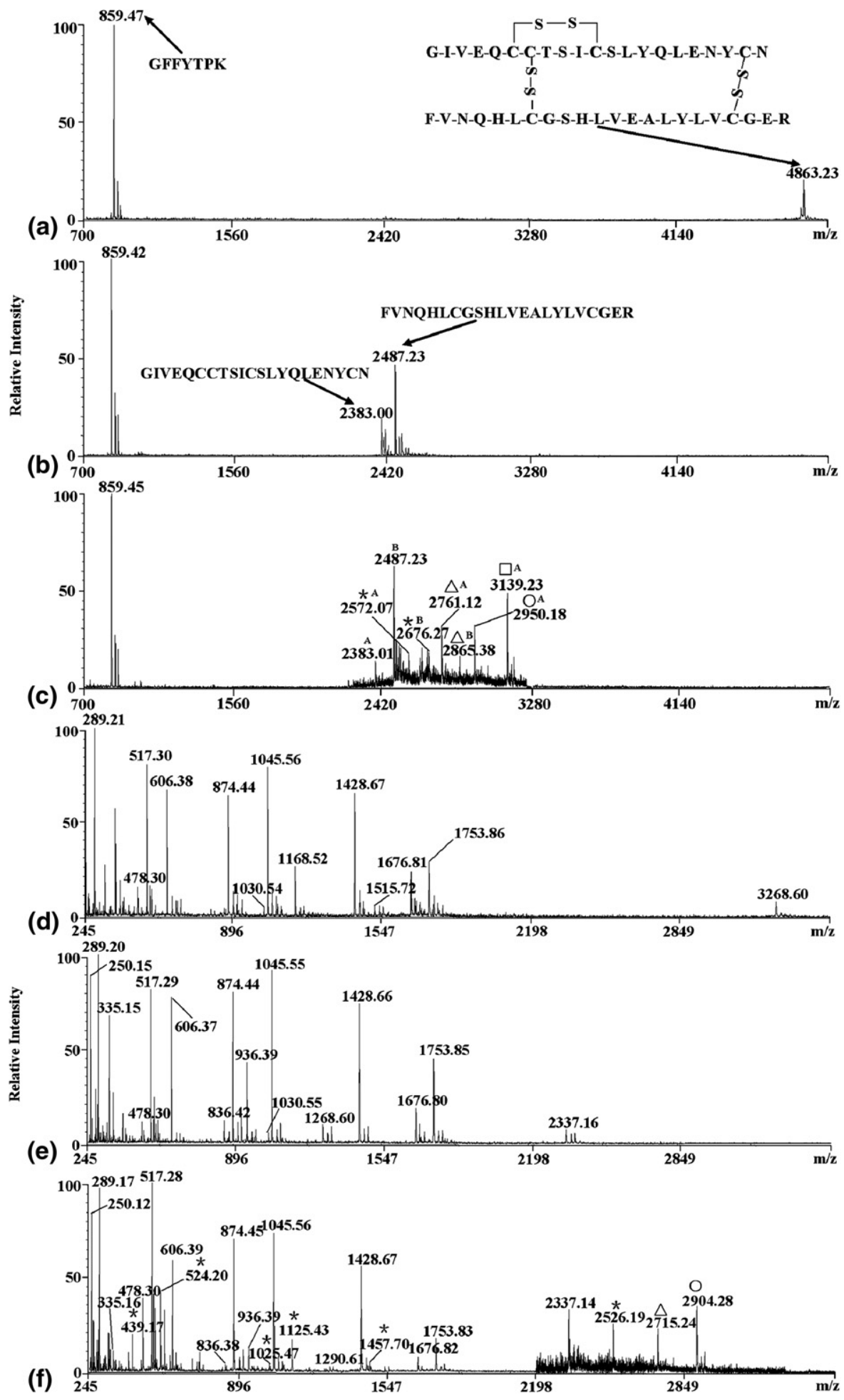

Figure 5. MALDI mass spectra of insulin (a)-(c) and lysozyme (d) and (e) tryptic digests using (a) and (d) CHCA as matrix, (b) and (e) obtained after on-target reduction by DTT using DHB as matrix, and (c) and (f) obtained after on-target reduction by DTT using CHCA as matrix in alkaline conditions. Signals marked with an asterisk are assigned to peptide-CHCA 1:1 adducts. Signals corresponding to peptide-CHCA 1:2 adducts are labeled with an open triangle. The filled circle indicates the ion peaks of peptide-CHCA 1:3 adducts. The ion peak of peptide-CHCA 1:4 adduct is marked with an open square. Signals in the mass range between 2250 and 3250 are enhanced by three times to make a clear annotation. Signals in the mass range between 2220 and 3280 are enhanced by six times to make a clear annotation. 
peptide of the B-chain (B1-B22) containing 2 cysteines $(\mathrm{m} / \mathrm{z}$ 2487.23) are observed. Thus, all three disulfide bonds of insulin were reduced. Nevertheless, by using CHCA as a matrix in Figure $5 c$, the measured monoisotopic mass peak of $m / z 2383.01$ migrated to 3139.23 for $[\mathrm{M}+\mathrm{H}]^{+}$; and the resulting mass shift of $756 \mathrm{u}$ indicates four cysteine residues. A further monoisotopic mass peak of $m / z 2487.23$ for $[\mathrm{M}+\mathrm{H}]^{+}$is shifted by 378 $\mathrm{Da}$, corresponding to two cysteine residues.

The mass spectra in Figure 5d-f clearly show the application of the method for mass spectrometric analysis of lysozyme. It has 129 amino acid residues containing eight cysteine residues, 17 potential cleavage sites for trypsin (Scheme 2). The observed and calculated masses of tryptic peptides related to disulfide bonds are listed in Table 1 . As shown in Figure 5d-f, signals such as at $m / z 289.2,517.3,874.4,1045.6,1428.7$, 1676.8 , and 1753.8 correspond to peptides that do not contain any cysteines. Comparing Figure $5 \mathrm{~d}$ with Figure 5e, peaks at $m / z 1168.52,1515.72$, and 3268.60 disappear, corresponding to disulfide-containing peptide fragments, and new ions at $\mathrm{m} / \mathrm{z} 936.39$ and 2337.16 are assigned to cysteine-containing peptide fragments. Comparing Figure $5 f$ with $5 \mathrm{e}$, we specifically screened for ion signals showing molecular mass shifts in increments of $189 \mathrm{u}$, corresponding to a CHCA addition to cysteine site. The fractions shown in Figure 5e and $\mathrm{f}$ both include a peak with a molecular mass of 2337 for $[\mathrm{M}+\mathrm{H}]^{+}$, which is shifted to $m / z 2904.28$ in Figure 5f, indicating three cysteine residues in the fragment. The peptide-matrix 1:1 adducts (labeled with an asterisk in the figure) are observed at $m / z$ 439.17, 524.20, 1025.47,
1125.43, and 1457.70, which indicate that there is only one cysteine residue in each fragment, and the observed values are quite close to those shown in Table 1.

Peptide-matrix adducts were also observed for both insulin and lysozyme using SA, FA, or CA as a matrix, even though the intensities of the signals were lower than those of CHCA adducts. According to our data, CHCA is the best matrix for the identification of disulfide bonds in proteins by MALDI-MS analysis.

\section{Conclusions}

Identifying the presence of a disulfide linkage in peptides is an essential part of protein analysis. A convenient method is developed to identify the disulfide-containing protein/peptides by using a specific modification of protein sulfhydryl groups with $\alpha$-, $\beta$-unsaturated matrices in on-target MALDI-MS analysis. The data presented here clearly demonstrate that CHCA and other commonly used matrices with $\alpha-$, $\beta$-unsaturated carboxyl group can be used to form peptide-matrix adducts with disulfidecontaining proteins/peptides after chemical reduction under alkaline conditions in the solution phase.

The on-target reduction method has the potential for simple and rapid identification of disulfide in peptides without resorting to the alkylation of disulfide bonds and HPLC separation. In the present study, we not only observed the formation of peptide-matrix adducts after chemical reduction in the MALDI mass spectra, but also discussed the mechanism of the generation of the adducts as well as the conditions to gain a better understanding and to broaden its applications. The evidence for the

Table 1. Disulfide-linked tryptic peptides generated from lysozyme before and after chemical reduction and cysteine residues with CHCA adducts

\begin{tabular}{|c|c|c|c|}
\hline Peptide position & Peptide sequence & Measured mass $(\mathrm{MH}+)^{\mathrm{a}}$ & Calculated mass $(\mathrm{MH}+)^{\mathrm{a}}$ \\
\hline cys 6 -cys 127 & $\begin{array}{l}\text { GCR } \\
\text { CELAAAMK }^{\mathrm{b}}\end{array}$ & 1168.52 & 1168.53 \\
\hline cys 30 -cys 115 & $\begin{array}{l}\text { CK } \\
\text { GYSLGNWVCAAK }^{b}\end{array}$ & 1515.72 & 1515.71 \\
\hline cys 64 -cys 80 & $\begin{array}{l}\text { WWCNDGR } \\
\text { NLCNIPCSALLSSDITASVNCAK }\end{array}$ & 3268.60 & 3268.56 \\
\hline $115-116$ & $\mathrm{CK}^{\mathrm{c}}$ & 250.15 & 250.12 \\
\hline $126-128$ & $\mathrm{GCR}^{\mathrm{c}}$ & 335.15 & 335.15 \\
\hline $6-13$ & CELAAAMK $^{\mathrm{c}}$ & 836.42 & 836.40 \\
\hline $62-68$ & WWCNDGR $^{\mathrm{C}}$ & 936.39 & 936.38 \\
\hline $22-33$ & GYSLGNWVCAAK $^{\mathrm{c}}$ & 1268.60 & 1268.61 \\
\hline $74-96$ & NLCNIPCSALLSSDITASVNCAK ${ }^{\mathrm{c}}$ & 2337.16 & 2337.12 \\
\hline $115-116$ & $\mathrm{CK}+1 \mathrm{CHCA}^{\mathrm{d}}$ & 439.17 & 439.16 \\
\hline $126-128$ & $\mathrm{GCR}+1 \mathrm{CHCA}^{\mathrm{d}}$ & 524.20 & 524.19 \\
\hline $6-13$ & CELAAAMK +1 CHCA $^{d}$ & 1025.47 & 1025.44 \\
\hline $62-68$ & WWCNDGR $+1 \mathrm{CHCA}^{\mathrm{d}}$ & 1125.43 & 1125.42 \\
\hline $22-33$ & GYSLGNWVCAAK $+1 \mathrm{CHCA}^{\mathrm{d}}$ & 1457.70 & 1457.65 \\
\hline $74-96$ & NLCNIPCSALLSSDITASVNCAK $+1 \mathrm{CHCA}^{\mathrm{d}}$ & 2526.19 & 2526.16 \\
\hline $74-96$ & NLCNIPCSALLSSDITASVNCAK $+2 \mathrm{CHCA}^{\mathrm{d}}$ & 2715.24 & 2715.20 \\
\hline $74-96$ & NLCNIPCSALLSSDITASVNCAK $+3 \mathrm{CHCA}^{\mathrm{d}}$ & 2904.28 & 2904.24 \\
\hline
\end{tabular}

a Monoisotopic mass.

b Disulfide-linked tryptic peptides from lysozyme.

c The peptides containing cysteine residues derived from reducing disulfide-linked tryptic peptides.

${ }^{\mathrm{d}}$ Peptide-matrix adducts. 
generation of peptide-matrix adducts occurring in solution phase instead of gas phase was provided. The mechanism of the nucleophilic addition reaction and the conditions to affect the formation of matrix adducts were proposed and studied. The $\mathrm{pH}$ of the solution is the most important factor to control the formation of the adducts.

All disulfide bonds in human insulin and lysozyme have been successfully examined using this new method. The number of disulfide bonds in peptides can be clearly deduced by the mass shift between the masses by using DHB matrix (or other matrices that cannot interact with protein sulfhydryl groups) and those by using CHCA matrix after reduction. The simplicity of the method makes it an attractive option for unequivocal identification of disulfide bonds in peptides/proteins.

\section{Acknowledgments}

The authors acknowledge support for this work by the National Natural Science Foundation of China (no. 2073137, 20675079). The authors thank Dr. David Mo for reading the manuscript.

\section{Appendix A Supplementary Material}

Supplementary material associated with this article may be found in the online version at doi:10.1016/ j.jasms.2009.08.020.

\section{References}

1. Lehle, K.; Kohnert, U.; Stern, A.; Popp, F.; Jaenicke, R. Effect of Disulfide Bonds on the Structure, Function, and Stability of the Trypsin/tPA Inhibitor from Erythrina caffra: Site-Directed Mutagenesis, Expression, and Physiochemical Characterization. Nat. Biotechol. 1996, 14, 476-480.

2. Wedemeyer, W. J.; Welker, E.; Narayan, M.; Scheraga, H. A. Disulfide Bonds and Protein Folding. Biochemistry 2000, 39, 4207-4216.

3. Reinders, J.; Sickmann, A. Modificomics: Post-translational Modifications Beyond Protein Phosphorylation and Glycosylation. Biomol. Eng. 2007, 24, 169-177.

4. Walewska, A.; Skalicky, J. J.; Davis, D. R.; Zhang, M. M.; Lopez-Vera, E.; Watkins, M.; Han, T. S.; Yoshikami, D.; Olivera, B. M.; Bulaj, G. NMR-Based Mapping of Disulfide Bridges in Cysteine-Rich Peptides: Application to the $\mu$-Conotoxin SxIIIA. J. Am. Chem. Soc. 2008, 130, $14280-14286$

5. von Ossowski, L.; Tossavainen, H.; von Ossowski, I.; Cai, C.; Aitio, O.; Fredriksson, K.; Permi, P.; Annila, A.; Keinänen, K. Peptide Binding and NMR Analysis of the Interaction between SAP97 PDZ2 and GluR-A: Potential Involvement of a Disulfide Bond. Biochemistry 2006, 45, 5567-5575.

6. Collins, E. S.; Wirmer, J.; Hirai, K.; Tachibana, H.; Segawa, S.; Dobson, C. M.; Schwalbe, H. Characterization of Disulfide-Bond Dynamics in Non-Native States of Lysozyme and Its Disulfide Deletion Mutants by NMR. Chem biochem. 2005, 6, 1619-1627.

7. Chait, B. T.; Field, F. H. A Rapid, Sensitive Mass Spectrometric Method for Investigating Microscale Chemical Reactions of Surface Adsorbed Peptides and Proteins. Biochem. Biophys. Res. Commun. 1986, 134, 420426

8. Patterson, S. D.; Katta, V. Prompt Fragmentation of Disulfide-Linked Peptides during Matrix-Assisted Laser Desorption Ionization Mass Spectrometry. Anal. Chem. 1994, 66, 3727-3732.

9. Huwiler, K. G.; Mosher, D. F.; Vestling, M. M. Optimizing the MALDITOF-MS Observation of Peptides Containing Disulfide Bonds. J. Biomol. Tech. 2003, 14, 289-297.

10. Foley, S. F.; Sun, Y.; Zheng, T. S.; Wen, D. Picomole-Level Mapping of Protein Disulfides by Mass Spectrometry Following Partial Reduction and Alkylation. Anal. Biochem. 2008, 377, 95-104.

11. Schnaible, V.; Wefing, S.; Bücker, A.; Wolf-Kümmeth, S.; Hoffmann, D. Partial Reduction and Two-Step Modification of Proteins for Identification of Disulfide Bonds. Anal. Chem. 2002, 74, 2386-2393.
12. Wu, W.; Huang, W.; Qi, J.; Chou, Y. T.; Torng, E.; Watson, J. T. 'Signature Sets', Minimal Fragment Sets for Identifying Protein Disulfide Structures with Cyanylation-Based Mass Mapping Methodology. J. Proteome Res. 2004, 3, 770-777.

13. Qi, J.; Wu, W.; Borges, C. R.; Hang, D.; Rupp, M.; Torng, E.; Watson, J. T. Automated Data Interpretation Based on the Concept of "Negative Signature Mass" for Mass-Mapping Disulfide Structures of Cystinyl Proteins. J. Am. Soc. Mass Spectrom. 2003, 14, 1032-1038.

14. Fukuyama, Y.; Iwamoto, S.; Tanaka, K. Rapid Sequencing and Disulfide Mapping of Peptides Containing Disulfide Bonds by Using 1,5-Diaminonaphthalene as a Reductive Matrix. J. Mass Spectrom. 2006, 41, 191-201.

15. Quinton, L.; Demeure, K.; Dobson, R.; Gilles, N.; Gabelica, V.; De Pauw E. New Method for Characterizing Highly Disulfide-Bridged Peptides in Complex Mixtures: Application to Toxin Identification from Crude Venoms. J. Proteome Res. 2007, 6, 3216-3223.

16. Demeure, K.; Quinton, L.; Gabelica, V.; De Pauw, E. Rational Selection of the Optimum MALDI Matrix for Top-Down Proteomics by In-Source Decay. Anal. Chem. 2007, 79, 8678-8685.

17. Huang, S. Y.; Wen, C. H.; Li, D. T.; Hsu, J. L.; Chen, C.; Shi, F. K.; Lin Y. Y. Assignment of Disulfide-Linked Peptides Using Automatic $\mathrm{a}_{1}$ Ion Recognition. Anal. Chem. 2008, 80, 9135-9140.

18. Schnaible, V.; Wefing, S.; Resemann, A.; Suckau, D.; Bücker, A.; WolfKümmeth, S.; Hoffmann, D. Screening for Disulfide Bonds in Proteins by MALDI In-Source Decay and LIFT-TOF/TOF-MS. Anal. Chem. 2002, $74,4980-4988$.

19. Zhang, M.; Kaltashov, I. A. Mapping of Protein Disulfide Bonds Using Negative Ion Fragmentation with a Broadband Precursor Selection. Anal. Chem. 2006, 78, 4820-4829.

20. Kim, H. I.; Beauchamp, J. L. Identifying the Presence of a Disulfide Linkage in Peptides by the Selective Elimination of Hydrogen Disulfide from Collisionally Activated Alkali and Alkaline Earth Metal Complexes. J. Am. Chem. Soc. 2008, 130, 1245-1257.

21. Gunawardena, H. P.; O'Hair, R. A.; McLuckey, S. A. Selective Disulfide Bond Cleavage in Gold(I) Cationized Polypeptide Ions Formed via Gas-Phase Ion/Ion Cation Switching I. Proteome Res. 2006, 5, 2087-2092.

22. Mihalca, R.; van der Burgt, Y. E.; Heck, A. J.; Heeren, R. M. Disulfide Bond Cleavages Observed in SORI-CID of Three Nonapeptides Complexed with Divalent Transition-Metal Cations. J. Mass Spectrom. 2007, $42,450-458$

23. Kim, H. I.; Beauchamp, J. L. Mapping Disulfide Bonds in Insulin with the Route 66 Method: Selective Cleavage of SOC Bonds Using Alkali and Alkaline Earth Metal Enolate Complexes. J. Am. Soc. Mass Spectrom. 2009, 20, 157-166.

24. Thakur, S. S. Balaram, P. Fragmentation of Peptide Disulfides Under Conditions of Negative Ion Mass Spectrometry: Studies of Oxidized Glutathione and Contryphan. J. Am. Soc. Mass Spectrom. 2008, 19, 358-366.

25. King, G. J.; Jones, A.; Kobe, B.; Huber, T.; Mouradov, D.; Hume, D. A.; Ross, I. L. Identification of Disulfide-Containing Chemical Cross-Links in Proteins Using MALDI-TOF/TOF-Mass Spectrometry. Anal. Chem. 2008, 80, 5036-5043.

26. Kalkhof, S.; Haehn, S.; Thling, C.; Paulsson, M.; Smyth, N.; Sinz, A. Determination of Disulfide Bond Patterns in Laminin $\beta_{1}$ Chain N-terminal Domains by Nano-High-Performance Liquid Chromatography/MatrixAssisted Laser Desorption/Ionization Time-of-Flight/Time-of-Flight Mass Spectrometry. Rapid Commun. Mass Spectrom. 2008, 22, 1933-1940.

27. Xu, H.; Zhang, L.; Freitas, M. A. Identification and Characterization of Disulfide Bonds in Proteins and Peptides from Tandem MS Data by Use of the MassMatrix MS/MS Search Engine. J. Proteome Res. 2008, 7 , $138-144$.

28. Happersberger, H. P.; Bantscheff, M.; Barbirz, S.; Glocker, M. O Multiple and Subsequent MALDI-MS On-Target Chemical Reactions for the Characterization of Disulfide Bonds and Primary Structures of Proteins. Methods Mol. Biol. 2000, 146, 167-184.

29. Spiess, C.; Happersberger, H. P.; Glocker, M. O.; Spiess, E.; Rippe, K.; Ehrmann, M. Biochemical Characterization and Mass Spectrometric Disulfide Bond Mapping of Periplasmic $\alpha$-Amylase MalS of Escherichia coli. J. Biol. Chem. 1997, 272, 22125-22133.

30. Beavis, R. C.; Chait, B. T. Cinnamic Acid Derivatives as Matrices for Ultraviolet Laser Desorption Mass Spectrometry of Proteins. Rapid Commun. Mass Spectrom. 1989, 3, 432-435.

31. Hutchens, T. W.; Nelson, R. W.; Li, C. M.; Yip, T. T. Synthetic Metal-Binding Protein Surface Domains for Metal Ion-Dependent Interaction Chromatography. I. Analysis of Bound Metal Ions by MatrixAssisted UV Laser Desorption Time-of-Flight Mass Spectrometry. J. Chromatogr. A 1992, 604, 125-132.

32. Huth-Fehre, T.; Gosine, J. N.; Wu, K. J.; Becker, C. H. Matrix-Assisted Laser Desorption Mass Spectrometry of Oligodeoxythymidylic Acids. Rapid Commun. Mass Spectrom. 1992, 6, 209-213.

33. Hamdan, M.; Bordini, E.; Galvani, M.; Righetti, P. G. Protein Alkylation by Acrylamide, Its N-Substituted Derivatives and Cross-Linkers, and Its Relevance to Proteomics: A Matrix Assisted Laser Desorption/IonizationTime of Flight-Mass Spectrometry Study. Electrophoresis 2001, 22, 16331644

34. Bordini, E.; Hamdan, M.; Righetti, P. G. Probing Acrylamide Alkylation Sites in Cysteine-Free Proteins by Matrix-Assisted Laser Desorption/ Ionization Time-of-Flight. Rapid Commun. Mass Spectrom. 2000, 14, $840-848$. 
35. Friedman, M.; Cavins, J. F.; Wall, J. S. Specific Modification of Protein Sulfhydryl Groups with $\alpha-, \beta$-Unsaturated Compounds. J. Am. Chem. Soc. 1965, 87, 3672-3682

36. Chiari, M.; Righetti, P. G.; Negri, A.; Ceciliani, F.; Ronchi, S. Preincubation with Cysteine Prevents Modification of Sulfhydryl Groups in Proteins by Unreacted Acrylamide in a Gel. Electrophoresis 1992, 13, $882-884$.
37. Bordini, E.; Hamdan, M.; Righetti, P. G. Probing the Reactivity of S-S Bridges to Acrylamide in Some Proteins Under High pH Conditions by Matrix-Assisted Laser Desorption/Ionization. Rapid Commun. Mass Spectrom. 1999, 13, 1818-1827.

38. Hunter, E. P. L.; Lias, S. G. Evaluated Gas Phase Basicities and Proton Affinities of Molecules: An Update. J. Phys. Chem. Ref. Data. 1998, 27 413-656. 